\title{
Dietary intake, blood lipid levels and insulin resistance in Malaysian adults
}

\author{
S.R Mitra ${ }^{1}$, P.Y Tan ${ }^{1}$ and Farahnaz Amini ${ }^{2}$ \\ ${ }^{1}$ School of Biological Sciences, Faculty of Science, University of Nottingham Malaysia Campus and ${ }^{2}$ School of Anti \\ Aging, Aesthetic \& Regenerative Medicine, UCSI University, Kula Lumpur Campus, Malaysia
}

Based on WHO, ATP III and IDF definitions prevalence of Metabolic Syndrome (MetS) is highest in Malaysia compared to other Asian countries ${ }^{1}$, presence of insulin resistance (IR) being a requisite for the diagnosis of MetS. IR is associated with increased risk for typeII Diabetes Mellitus and cardiovascular diseases ${ }^{2}$

To evaluate blood biochemical parameters, anthropometric indices and dietary intake and correlation of the latter with insulin resistance in apparently healthy Malaysians.

Insulin resistance was evaluated using the homeostasis model assessment of insulin resistance (HOMA-IR) and calculated as fasting glucose $(\mathrm{mmol} / \mathrm{L}) *$ insulin $(\mu \mathrm{IU} / \mathrm{mL}) / 22 \cdot 5^{3}$

Malaysians of all three ethnic categories (Malays, Chinese and Indians), 18 years old and above with BMI > 23, attending a specialist health care centre in Semenyih, are being invited to participate in the current study.

So far 16 female and 5 male participants have been assessed. Mean $( \pm S D)$ age was $32.9 y( \pm 10 \cdot 9)$ for women and $30 \cdot 8 \mathrm{y}( \pm 9 \cdot 1)$ for male participants. Average BMI for all was $29.9 \mathrm{~kg} / \mathrm{m}^{2}( \pm 3.6)$ significantly higher $(\mathrm{P}=0.01)$ than $23 \mathrm{~kg} / \mathrm{m}^{2}$ which is the current cut off for categorisation as 'overweight' for South East Asian individuals. Mean fat mass for females was $31.7 \mathrm{~kg}( \pm 6 \cdot 7)$ and for the male was $35.1 \mathrm{~kg}( \pm 13.2)$. Mean body fat percentage was $41.8 \%( \pm 6.3)$ for females (normal range: $18 \sim 28)$ and $38.4 \%( \pm 5.4)$ for the male (normal range: $10 \sim 20)$. Mean waist circumference was $85.9 \mathrm{~cm}( \pm 6 \cdot 5)$ for females (normal: 80$)$ and $106 \cdot 2( \pm 15 \cdot 2) \mathrm{cm}$ for the male (normal: 90). The average blood bio-chemical parameters for all participants were as follows: total blood cholesterol 6.0 mmol/L $( \pm 0.9)$ (normal <5.2); blood triglycerides $1.8 \mathrm{mmol} / \mathrm{L}( \pm 1.6)$ (normal <1.7); HDL cholesterol $1.8 \mathrm{mmol} / \mathrm{L}( \pm 0.6)(\mathrm{normal}>1.0)$; LDL cholesterol $3.4 \mathrm{mmol} / \mathrm{L}( \pm 0 \cdot 9)$ (optimal $<2 \cdot 6)$.

There is a positive correlation between insulin resistance with, blood triglyceride, total blood cholesterol and blood LDL cholesterol levels in females $(r=0 \cdot 48, r=0 \cdot 11 . r=0 \cdot 4$, respectively). In the combined data with both gender, we found significant negative correlation between insulin resistance and blood HDL cholesterol levels $(r=0.63, p=0.03)$. Percentage of dietary fat contributing to total calorie intake was $43.3 \%( \pm 3 \cdot 8)$ significantly higher than the recommendation-30\% $(\mathrm{P}=0.006)$.

We propose dietary and lifestyle changes in insulin resistant individuals to tackle obesity related non-communicable diseases in Malaysian adults.

Ethical approval was obtained from the UNMC faculty of Science Research Ethics Committee.

1. Mohamud WWN, Ismail AS, Sharifuddin A et al. (2010). Prevalence of metabolic syndrome and its risk factors in Malaysians: results of a nationwide survey, J. diabres 91: 239-245.

2. McLaughlin T, Abbasi F, Cheal K et al. (2003). Use of metabolic markers to identify overweight individuals who are insulin resistant. Ann Intern Med 139:802-809.

3. Mathews DR, Hosker JP, Rudenski AS, Naylor BA, Treacher DF, Turner RC (1985). Homeostasis model assessment: insulin resistance and B-cell function from fasting plasma glucose and insulin concentrations in man. Diabetologia 28, 412-9. 